\title{
Rapid and sensitive detection of rare cancer cells by the coupling of immunomagnetic nanoparticle separation with ELISA analysis
}

This article was published in the following Dove Press journal:

International Journal of Nanomedicine

16 June 2012

Number of times this article has been viewed

\author{
Hao-Yuan Cheng' \\ Lee-Jene Lai ${ }^{2}$ \\ Fu-Hsiang Ko'
}

'Department of Materials Science and Engineering, National Chiao Tung

University, Taiwan, Republic of China;

${ }^{2}$ National Synchrotron Radiation

Research Center, Taiwan, Republic of China
Correspondence: Hao-Yuan Cheng National Chiao Tung University, I00I University Road, Hsinchu,

Taiwan, Republic of China

Tel +88 635780281

Fax +88635789816

Email haoyuan818.nano97g@g2.nctu. edu.tw

\begin{abstract}
This study presents a rapid and sensitive method for detecting cancer cells occurring at low concentration. The method involves the simultaneous detection of two biomarkers of $\mathrm{T}$ helper cancer cells. One biomarker conjugates with immunofunctionalized magnetic nanoparticles (MNPs), enabling the separation of the T helper cells from a mixed population of cells. The other biomarker is used for detection during enzyme-linked immunosorbent assay (ELISA) analysis. The specific $\mathrm{T}$ helper cells can be quantified according to their ELISA absorbance values following magnetic separation. The experimental results demonstrate that immunofunctionalized MNPs can function as magnetic sensors and separate specific T helper cells from a mixed population with high efficiency and high specificity. Coupled with the ELISA technique, the immunofunctionalized MNPs can simultaneously detect rare cells. Results indicated increasing absorbance with increasing $\mathrm{T}$ cell number (from 10 to $10^{6}$ ). The total detection time was less than 15 minutes, even at a low $\mathrm{T}$ cell count. The advantages of the proposed method for detecting specific cells at low concentration include ease of preparation, low cost, rapid detection, and high sensitivity. The proposed system can be adopted to detect circulating tumor cells in early tumor stages for diagnostic or prognostic purposes.
\end{abstract}

Keywords: ELISA, magnetic nanoparticles, immunoassay, cancer cell

\section{Introduction}

In biotechnological research, the development of methods that enable the rapid and sensitive detection of rare cells and the early diagnosis, staging, and prognosis of viral infections or cancer has become a high priority. ${ }^{1,2}$ Systems to rapidly and sensitively detect low-frequency cancer cells have the potential to significantly improve cancer diagnosis and prognosis., In the human circulatory system, particularly in the blood, the number of circulating tumor cells is closely correlated with the recurrence of cancer and relapse. During the early stages of a tumor, cells circulate in the blood at extremely low concentrations, and their detection is thus a difficult task. ${ }^{5}$ The conventional methods for detecting trace cells are culture techniques and enzyme-linked immunospot assays. These require increasing cell numbers by culturing in vitro or by incubating with specific peptides ${ }^{6,7}$ Studies have reported other approaches, based on flow cytometry, to detect low-frequency cells for the prognosis of minimal residual disease in childhood acute lymphoblastic leukemia. ${ }^{8-10}$ However, detecting numerous cells is a relatively labor-intensive and time-consuming process when using enzymelinked immunospot or flow cytometric approaches. Developing highly sensitive and rapid methods of detecting specific cancer cells occurring at low frequency after appropriate treatment is, therefore, of significant prognostic value. 
Immunological methods provide powerful tools for the chemical detection of proteins in situ. The enzyme-linked immunosorbent assay (ELISA) is one of the most commonly used techniques for the detection and quantification of antibodies, antigens, hormones, cytokines, and various other molecules, including synthetic peptides. Because of its quantitative, sensitive, and rapid response, the use of ELISA in research and clinical laboratories has become widespread. ${ }^{11,12}$ In addition, immunomagnetic separation has been shown to be a simple, fast, and efficient method of isolating specific micrometastatic cells from colorectal cancer and stem cells. ${ }^{13,14}$

The present study demonstrates a high-throughput and sensitive method for detecting cells occurring in low numbers, using specific immunofunctionalized magnetite nanoparticles (MNPs) coupled with the ELISA technique. Human Jurkat cells ( $\mathrm{T}$ helper lymphocytes) provided a model for circulating tumor cells, with antibodies and immunofunctionalized MNPs targeting CD3 and CD4 markers, respectively, on the $\mathrm{T}$ helper cell membrane. Human $\mathrm{C} 1 \mathrm{R}$ cells (B lymphocytes) provided the other cells in the mixed population. Experimental results indicated that the detection of specific cells occurs within approximately 15 minutes, even at a low cell number, and that the sensitivity for distinction of specific $\mathrm{T}$ helper lymphocytes from $\mathrm{B}$ cells is approximately $0.001 \%$. The proposed system thus provides a rapid and sensitive method for detecting and quantifying rare cells.

\section{Materials and methods}

\section{Chemical materials}

Chemicals such as iron (III) chloride hexahydrate $\left(\mathrm{FeCl}_{3} \cdot 6 \mathrm{H}_{2} \mathrm{O}\right)$, 3-aminopropyltriethoxysilane (APTES), glutaraldehyde solution, $10 \times$ concentrated phosphate buffered saline $(10 \times$ PBS) (diluted to $1 \times$ PBS using ultrapure water for further use), and 3,3',5,5'-tetramethylbenzidine were obtained from Sigma-Aldrich (St Louis, MO). Iron (II) chloride tetrahydrate $\left(\mathrm{FeCl}_{2} \cdot 4 \mathrm{H}_{2} \mathrm{O}\right)$ was obtained from Alfa Aesar (Ward Hill, MA). The reagents ammonium hydroxide $\left(\mathrm{NH}_{4} \mathrm{OH}\right)$ and horseradish peroxidase-streptavidin (HRP-stv) were purchased from J.T. Baker (Covidien, Mansfield, MA) and Thermo Scientific (Thermo Fisher Scientific). Human T helper lymphocytes (ATCC TIB-152, Jurkat cell line) and human B lymphocytes (ATCC CRL-1993, C1R) were obtained from the American Type Culture Collection (Manassas, VA). Anti-human CD4 (14-0049) and biotinylated anti-human CD3 (13-0038) antibodies were purchased from eBioscience, Inc (San Diego, CA). Ultrapure water (18 M $\Omega \mathrm{cm})$, obtained using a Milli-Q purification system (Millipore, MA), was used for the preparation of all solutions.

\section{Cell culture}

The Jurkat cells ( $\mathrm{T}$ helper lymphocytes) were maintained in an RPMI-1640 medium (11875, Gibco ${ }^{\circledR}$; Life Technologies, Carlsbad, CA) supplemented with 25 mm HEPES (SH30237, HyClone; Thermo Fisher Scientific, Waltham, MA), 10\% (v/v) heat-inactivated fetal clone III serum (SH30109; Hyclone), $1 \%$ penicillin (P0781; Sigma-Aldrich), and $0.005 \mathrm{mM}$ 2-Mercaptoethanol (M7522; Sigma-Aldrich) at $37^{\circ} \mathrm{C}$ and $5 \% \mathrm{CO}_{2}$. The $\mathrm{C} 1 \mathrm{R}$ cells (B lymphocytes) were cultured in an Iscove's Modified Dulbecco's medium (12200-028, Gibco; Life Technologies), supplemented with $10 \%$ (v/v) heat-inactivated fetal clone III serum and $1 \%$ penicillin at $37^{\circ} \mathrm{C}$ and $5 \% \mathrm{CO}_{2}$ in a humidified atmosphere. A hemocytometer was used to count the number of cells in the cultured solutions. Cells were then concentrated by centrifuging or diluted and washed with $1 \times$ phosphate buffered saline (PBS) for further use.

\section{Transmission electron microscopy}

For preparation of the samples for transmission electron microscopy, the particles were placed on a copper mesh surface for critical point drying using $\mathrm{CO}_{2}$ (CPD 030; Leica Microsystems [Bal-Tec], Wetzlar, Germany). The morphology of the sample was observed using a JEOL (Tokyo, Japan) 2010F transmission electron microscope.

\section{Experimental protocols}

MNPs were synthesized according to the following procedure. Iron (II) chloride tetrahydrate and $\mathrm{FeCl}_{3} \cdot 6 \mathrm{H}_{2} \mathrm{O}$ were mixed in the ratio $\mathrm{Fe}^{+2}: \mathrm{Fe}^{+3}=1: 2$ and dissolved in ultrapure water. The mixtures were then placed in a water bath maintained at $80^{\circ} \mathrm{C}$, and aqueous $\mathrm{NH}_{4} \mathrm{OH}$ solution $(8 \mathrm{M})$ was added until a black precipitate appeared. The mixture was stirred continuously for 30 minutes in the $80^{\circ} \mathrm{C}$ water bath. When the reaction was complete, the MNPs in the solution were isolated using a magnet and washed repeatedly with hot water to remove any unreacted impurities. The synthesized MNPs were reacted with APTES overnight to create MNPs-APTES. To introduce functional immunoglobulin on the particles, glutaraldehyde was conjugated to the terminal $\mathrm{NH}_{2}$ group of MNPs-APTES. Excess anti-CD4 antibodies were added to create the immunofunctionalized MNPs.

For immunomagnetic separation, anti-CD4 MNPs were introduced to the mixture of $\mathrm{T}$ helper cells and $\mathrm{B}$ lymphocytes for 15 minutes on ice, yielding MNP-bound T cells. The suspension of the mixed cell population containing these MNP-bound T cells was transferred into a new tube, and $1 \times$ PBS solution was added to reach a total volume of $1.5 \mathrm{~mL}$. The tube was loaded onto the magnet for separation 
of the immunomagnetic particles from the mixed cells. The supernatant fraction was pipetted off, leaving the immunomagnetically labeled specific $\mathrm{T}$ helper cells remaining in the tube. The immunomagnetic separation procedure was conducted three times.

The specific lymphocytes were then detected using ELISA. Four $\mu \mathrm{L}$ of biotinylated anti-human CD3 antibody and HRP-stv were added to $100 \mu \mathrm{L}$ of the separated Thelper cells and incubated at room temperature for 15 minutes. The samples were washed with $1 \times$ PBS to remove unreacted matter, and 3,3'-,5,5'-tetramethylbenzidine was added for ELISA detection through measurement of absorbance at $650 \mathrm{~nm}$ $\left(\mathrm{OD}_{650}\right)$. Detection was done using the $\mathrm{EMax}^{\circledR}$ endpoint ELISA microplate reader (Molecular Devices, Sunnyvale, CA), running SoftMax ${ }^{\circledR}$ Pro analysis software (Molecular Devices Corporation, Sunnyvale, CA). During detection, correction was done using $\mathrm{B}$ cells as blanks.

\section{Results and discussion Proof of concept}

The present study demonstrates a method for rapid and sensitive detection of specific lymphocytes occurring at low frequency using immunofunctionalized MNPs and ELISA analysis. Figure 1A displays the methods employed for synthesis of MNPs using $\mathrm{Fe}^{+2}$ - and $\mathrm{Fe}^{+3}$-containing materials. Synthesis of the MNPs occurred after treatment of the $\mathrm{Fe}^{+2} / \mathrm{Fe}^{+3}$ mixtures with alkaline solution in a water bath maintained at $80^{\circ} \mathrm{C}$. Reaction of the MNPs with APTES then led to the formation of MNPs-APTES. To introduce functional immunoglobulin onto the particles, glutaraldehyde was conjugated to the terminal $\mathrm{NH}_{2}$ group of MNPs-APTES. The addition of excess anti-CD4 antibodies then created the immunofunctional MNPs. As shown in Figure 1B and C, the antigens on the membranes of the $\mathrm{T}$ helper cells differ from those on the membranes of the B cells. All $\mathrm{T}$ helper cell membranes contain the markers $\mathrm{CD} 3$ and $\mathrm{CD} 4$, whereas the membranes of B cells contain CD19 and CD40 markers. The presented method takes advantage of these characteristics, using the $\mathrm{CD} 3$ and $\mathrm{CD} 4$ biomarkers to distinguish the $\mathrm{T}$ helper cells (targets) from the B cells. The tight binding affinity of biotin-streptavidin ${ }^{15-17}$ enables linkage to the target $\mathrm{T}$ helper cells through biotinylated anti-CD3 antibody and HRP-stv. The membranes of the T helper cells thus conjugated with anti-human CD4-MNPs through the antigenantibody reaction, yielding the MNP-bound T helper cells. After selection using a magnet, the membranes of the $\mathrm{T}$ helper cells were associated with biotin-conjugated anti-human CD3 antibodies and HRP-stv, creating the labeled T cells.
A

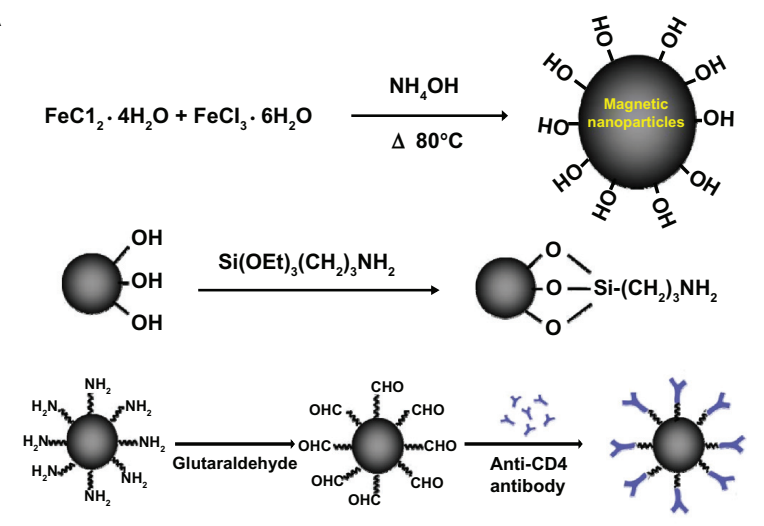

B
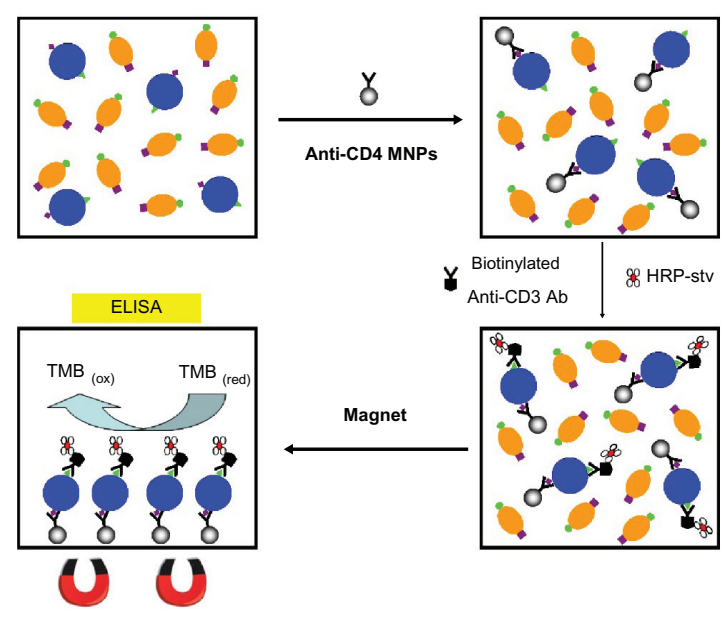

C
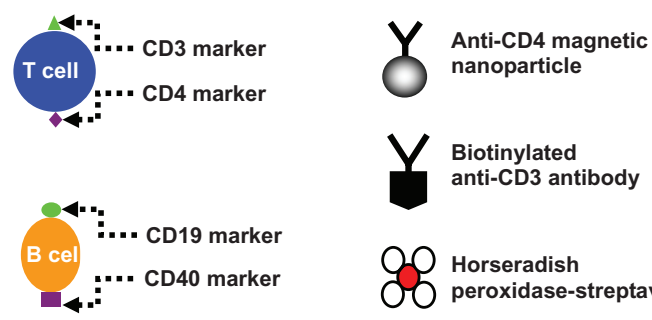

QP Horseradish

00 peroxidase-streptavidin

Figure I (A) Synthesis of MNPs and immunofunctionalized MNPs. (B) The schema illustrates the process for detection of specific $T$ helper cells using two biomarkers: immunofunctionalized MNPs for immunoseparation and the ELISA technique for detection. Absorbance was recorded at a wavelength of $650 \mathrm{~nm}$. (C) Diagrammatic representations of the $T$ helper cells, B cells, and other materials.

Abbreviations: MNPs, magnetite nanoparticles; ELISA, enzyme-linked immunosorbent assay; HRP-stv, horseradish peroxidase-streptavidin; TMB, 3,3',5,5'tetramethylbenzidine.

Following the catalysis of $3,3^{\prime}, 5,5^{\prime}$-tetramethylbenzidine, the isolated $\mathrm{T}$ helper cells could be quantified according to their ELISA absorbance values.

\section{Morphology evaluation}

To verify the dimensions of the synthesized MNPs, transmission electron microscopy images were evaluated (Figure 2). The MNPs were spherical, with a uniform diameter (Figure 2A). The APTES-modified MNPs were also spherical 
A

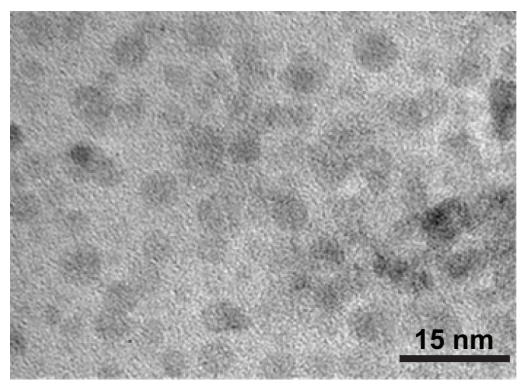

B

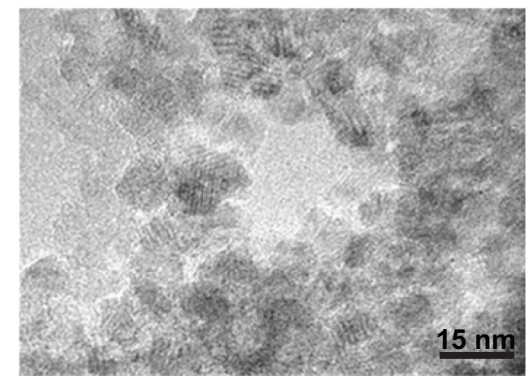

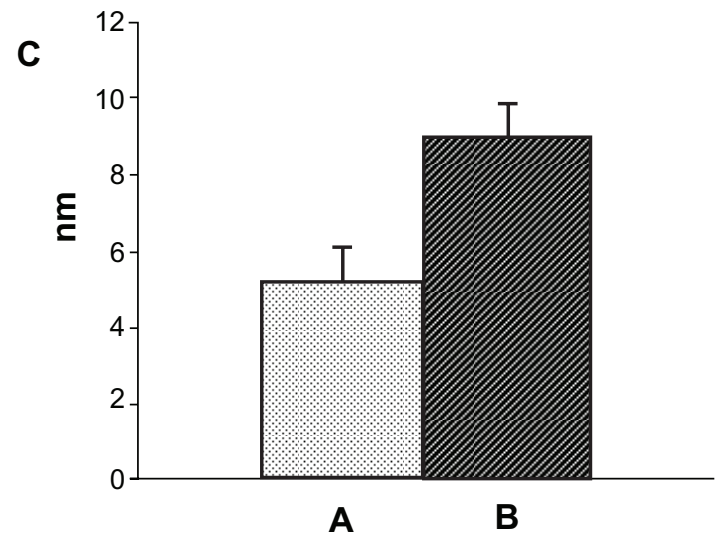

Figure 2 Typical transmission electron microscopy images of $(\mathbf{A})$ synthesized MNPs and (B) APTES-modified MNPs, with (C) a bar chart indicating their respective average diameters.

Abbreviations: MNPs, magnetite nanoparticles; APTES, 3-aminopropyltriethoxysilane.

in transmission electron microscopy images (Figure 2B). Figure $2 \mathrm{C}$ shows the diameters of the MNPs (less than $6 \mathrm{~nm}$ ) and the APTES-modified MNPs (less than $10 \mathrm{~nm}$ ).

\section{Phase identification}

Previous studies have demonstrated that varying the preparation conditions of ferrites can create versatile magnetites. ${ }^{18,19} \mathrm{In}$ the present study, the X-ray diffraction technique was selected for MNP identification. Phase identification of the samples was performed with a BL01C2 X-ray powder diffraction beamline in the National Synchrotron Radiation Research Center, using an X-ray wavelength of $0.688807 \AA$. Figure $3 \mathrm{~A}-\mathrm{C}$, and $3 \mathrm{D}$ represent the spectra of $\alpha-\mathrm{Fe}_{2} \mathrm{O}_{3}, \mathrm{Fe}_{3} \mathrm{O}_{4}, \mathrm{MNPs}$, and the APTES-modified MNPs, respectively. The diffraction peaks in Figure $3 \mathrm{C}$ are more consistent with those in Figure 3B than those in Figure 3A, indicating that the MNPs are more similar to $\mathrm{Fe}_{3} \mathrm{O}_{4}$ than to $\alpha-\mathrm{Fe}_{2} \mathrm{O}_{3}$. The diffraction pattern of Figure 3D is identical to that of Figure $3 \mathrm{C}$, indicating that APTES is amorphous. This suggests that APTES modifies MNPs yet has no apparent effects on their crystalline structures.

\section{Structural characterization}

Fourier transform infrared spectra were obtained using a BL14A1 beamline at the National Synchrotron Radiation
Research Center and used to characterize the APTES-modified MNPs and immunofunctionalized MNP composites. The spectra were compared with the MNP results. As shown in Figure 4A, the Fourier transform infrared spectrum of the MNPs displays a characteristic broad peak, from approximately $3000 \mathrm{~cm}^{-1}$ to approximately $3500 \mathrm{~cm}^{-1}$, assigned to the stretching vibration of $\mathrm{O}-\mathrm{H}$ groups on the MNPs. In Figure 4B, the spectrum of the APTES-modified MNPs displays a further peak at approximately $1020 \mathrm{~cm}^{-1}$, corresponding to the $\mathrm{Si}-\mathrm{O}$ stretching vibration. Common biomolecules, such as nucleic acids, proteins, lipids, and carbohydrates, have characteristic and well-known vibration fingerprints, which can be identified using infrared spectroscopy. ${ }^{20}$ As shown in Figure 4C, the spectrum of the anti-CD4 immunofunctionalized MNPs displays peaks that are frequently observed in biological samples, including lipids (at approximately $2900 \mathrm{~cm}^{-1}$ ), amide I (at approximately $1650 \mathrm{~cm}^{-1}$ ), and amide II (at approximately $1549 \mathrm{~cm}^{-1}$ ), representing stretching vibrations of the antibody signature. These results indicated the successful creation of antiCD4 immunofunctionalized MNPs during multiple stages.

\section{Specific binding and separation ability}

Specificity after conjugation was verified using the antigen-antibody recognition reaction occurring between 


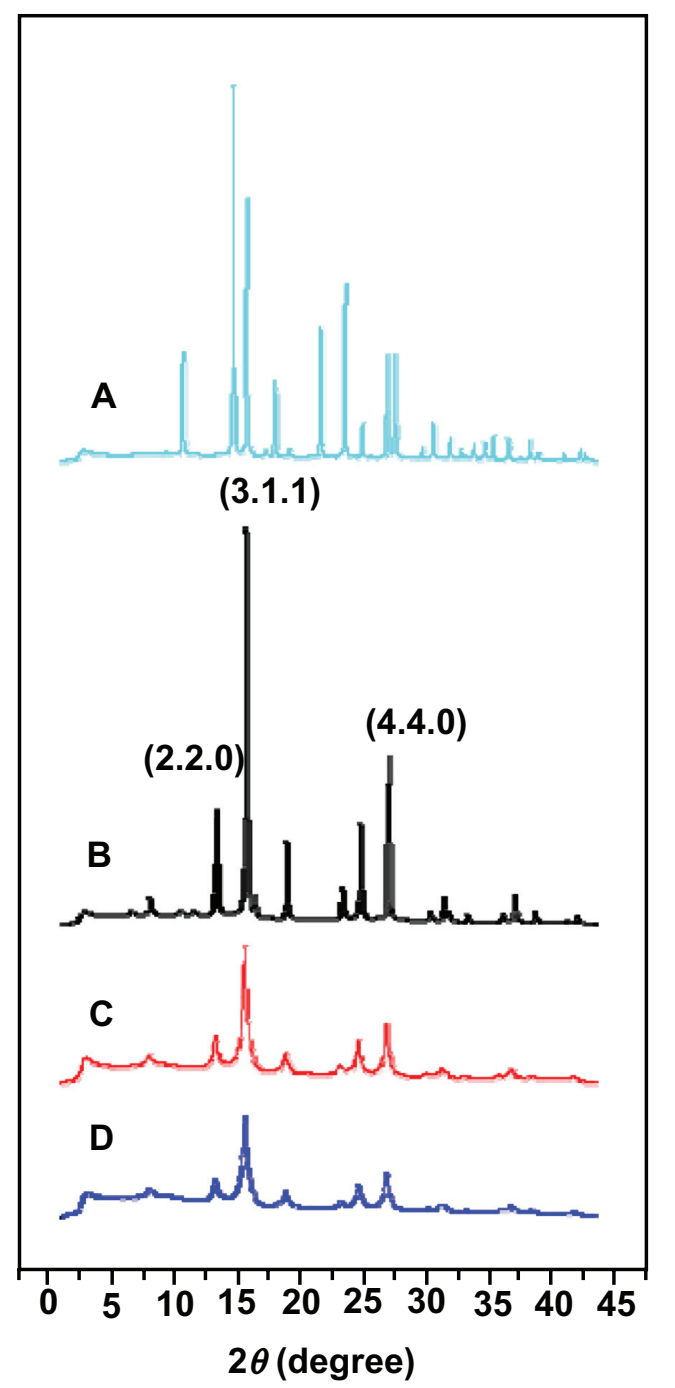

Figure 3 Synchrotron XRD spectra of (A) $\alpha-\mathrm{Fe}_{2} \mathrm{O}_{3}$, (B) $\mathrm{Fe}_{3} \mathrm{O}_{4^{\prime}}$ (C) MNPs, and (D) APTES-modified MNPs.

Abbreviations: XRD, X-ray diffraction; MNPs, magnetite nanoparticles; APTES, 3-aminopropyltriethoxysilane.

the CD3 markers of the T helper cells and biotinylated anti-human $\mathrm{CD} 3$, followed by a coupling reaction between biotinylated anti-human CD3 and HRP-stv and between the CD4 marker of the T helper cells and anti-human CD4-conjugated MNPs. Incubation of the T cells with first the anti-human CD4-conjugated MNPs, then biotinylated anti-human CD3, and finally, HRP-stv led to the formation of the HRP-tagged MNP-bound T cells. Figure 5A shows the specificity of the magnetic separation process for the $\mathrm{T}$ helper cells, following the sequential incubation of $10^{6} \mathrm{~T}$ cells and $10^{6} \mathrm{~B}$ cells with anti-human CD4-conjugated MNPs, biotinylated anti-human CD3, and HRP-stv. A high proportion of the target $\mathrm{T}$ helper cells were captured. In contrast, most of the B cells were not captured, despite the high cell count $\left(10^{6}\right)$. This indicated that the anti-human CD4-conjugated

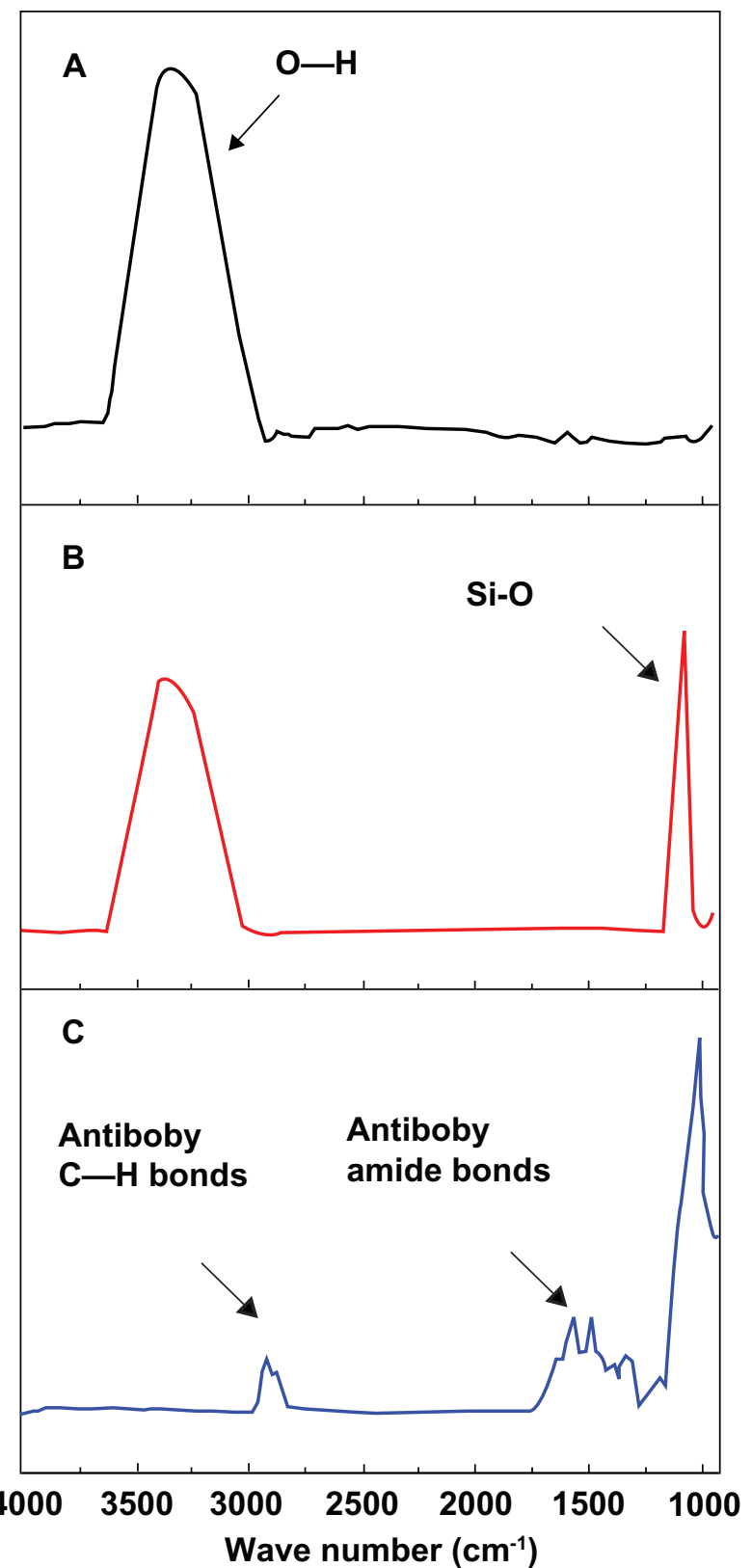

Figure 4 Synchrotron Fourier transform infrared spectra of (A) MNPs, (B) APTESmodified MNPs, and (C) immunofunctionalized MNPs.

Abbreviations: MNPs, magnetite nanoparticles; APTES, 3-aminopropyltriethoxysilane.

MNPs successfully attached to the membranes of $\mathrm{T}$ helper cell through the direct specificity of the antigen-antibody reaction and that cross-reaction with nontarget $\mathrm{B}$ cells did not occur. The separation ability was evaluated using different numbers of $\mathrm{T}$ helper cells, from approximately $10^{4}$ to $10^{6}$, with results indicating an efficiency of almost $90 \%$ (Figure 5B). The experimental results further demonstrated that the anti-CD4 immunofunctionalized MNPs could function as a magnetic sensor, separating $T$ helper cells with high specificity and separation efficiency. When coupled with 
A

T cells
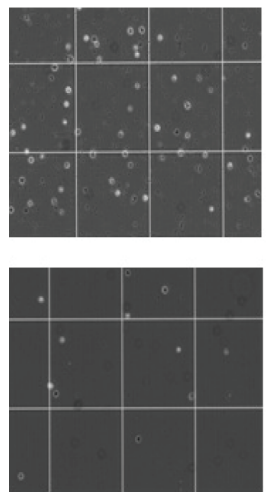

Upper row image: MNP-captured cells

Lower row image: uncaptured cells
B

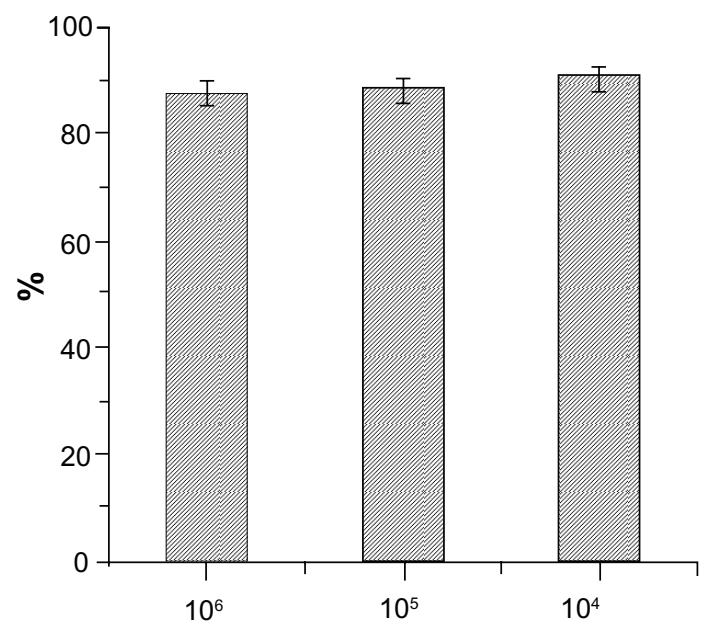

Number of specific T cells

Figure 5 (A) Optical microscopic images indicating the specificity of immunofunctionalized MNPs for the T helper cells during magnetic separation and (B) a bar chart indicating the separation efficiency of immunofunctionalized MNPs at various $T$ cell counts.

Abbreviation: MNPs, magnetite nanoparticles.

the ELISA technique, the anti-CD4 immunofunctionalized MNPs provide the further advantage of being able to detect rare cells.

\section{Detection of T helper cells in a mixed cell population using ELISA}

Following the sequential incubation of cells with anti-CD4 immunofunctionalized MNPs, biotinylated anti-human CD3, and the HRP-stv catalytic probe, a magnet was applied to separate the specific CD3- and MNP-labeled T helper cells. The separated $\mathrm{T}$ helper cell population was then quantified by measuring the absorbance according to CD3-labeling. Figure 6 displays the absorbance and T helper cell population

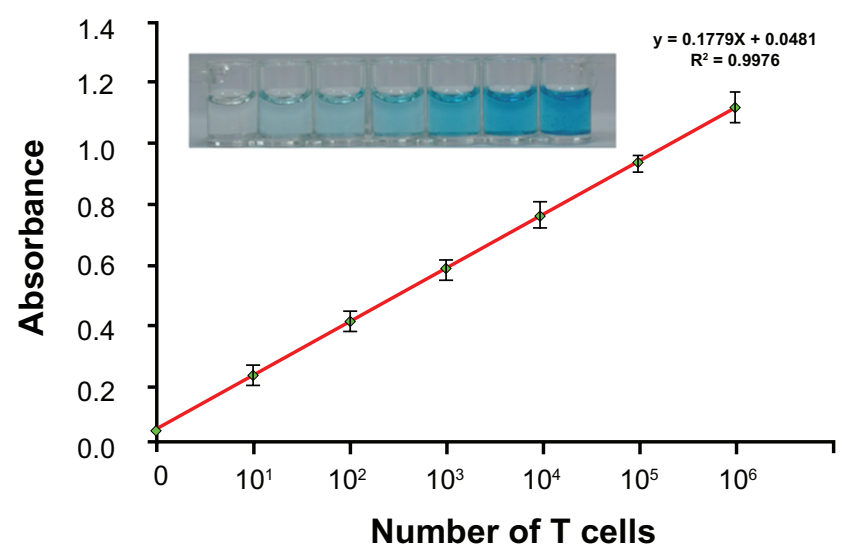

Figure 6 Semi-log plot of absorbance and the number of T helper cells detected by ELISA in a mixed cell population.

Abbreviation: ELISA, enzyme-linked immunosorbent assay. number (from 0 to approximately $10^{6}$ cells) following magnetic separation from the B cells. Absorbance was recorded at a wavelength of $650 \mathrm{~nm}$. Experimental results indicated increasing absorbance of the CD3-labeled T cells with increasing $\mathrm{T}$ helper cell quantity (from 10 to $10^{6}$ ) in a mixed population with B cells. Detection time was less than 15 minutes, including the scanning period, even at a low $\mathrm{T}$ cell count. These results indicated that the system has high sensitivity for the detection of specific rare cells from a mixed cell population.

\section{Conclusion}

This study presents an efficient, specific, and sensitive method for detecting cancer cells occurring at low concentration using ELISA and MNPs as probes. After functionalization of the surfaces of the MNPs using APTES, the antibody is covalently immobilized on the MNPs. The immobilized molecules retain their specific binding activity. The immunofunctionalized MNPs display high ability to capture and separate target cancer cells. Coupled with the ELISA technique, they can detect specific $\mathrm{T}$ cells from a mixed $\mathrm{B}$ cell- $\mathrm{T}$ cell population. Absorbance increases with increasing $\mathrm{T}$ cell population (from 10 to $10^{6}$ cells). The immunofunctionalized MNPs have approximately 90\% separation efficiency and approximately $0.001 \%$ detection sensitivity for specific T helper lymphocytes from B cells, with detection occurring within 15 minutes. The anti-CD4-conjugated MNPs can, therefore, function as magnetic sensors and separate specific 
T helper cells from a mixed cell population, with HRP-stv coupled with anti-CD3 biotin providing a reliable ELISA platform for $\mathrm{T}$ cell detection. The advantages of the system include ease of manipulation, low cost, rapid detection, and high sensitivity. In the future, the proposed method could be applied for the detection of Epstein Barr virus-specific memory $\mathrm{T}$ lymphocytes in nasopharyngeal carcinoma patients and could prove useful for the early diagnosis, staging, and prognosis of cancer diseases.

\section{Disclosure}

The authors report no conflicts of interest in this work.

\section{References}

1. Gross HJ, Verwer B, Houck D, Hoffman RA, Recktenwald D. Model study detecting breast cancer cells in peripheral blood mononuclear cells at frequencies as low as $10^{-17}$. Proc Natl Acad Sci U S A. 1995;92(2):537-541.

2. Sha MY, Xu H, Natan MJ, Cromer R. Surface-enhanced Raman scattering tags for rapid and homogeneous detection of circulating tumor cells in the presence of human whole blood. J Am Chem Soc. 2008;130:17214-17215.

3. Li G, Cuilleron M, Gentil-Perret A, et al. Rapid and sensitive detection of messenger RNA expression for molecular differential diagnosis of renal cell carcinoma. Clin Cancer Res. 2003;9:6441-6446.

4. Ishii T, Fujiwara Y, Ohnaka S, et al. Rapid genetic diagnosis with the transcription-reverse transcription concerted reaction system for cancer micrometastasis. Ann Surg Oncol. 2004;11:778-785.

5. Pantel K, Otte M. Occult micrometastasis: enrichment, identification and characterization of single disseminated tumour cells. Semin Cancer Biol. 2001;11:327-337.

6. Pahar B, Li J, Rourke T, Miller CJ, McChesney MB. Detection of antigen-specific $\mathrm{T}$ cell interferon $\gamma$ expression by ELISPOT and cytokine flow cytometry assays in rhesus macaques. J Immunol Methods. 2003;282:103-115.

7. Alix-Panabières C, Rebillard X, Brouillet JP, et al. Detection of circulating prostate-specific antigen-secreting cells in prostate cancer patients. Clin Chem. 2005;51:1538-1541.
8. Fornas O, Garcia J, Petriz J. Flow cytometry counting of CD34+ cells in whole blood. J Nat Med. 2000;6:833-836.

9. Bajaj S, Welsh JB, Leif RC, Price JH. Ultra-rare-event detection performance of a custom scanning cytometer on a model preparation of fetal nRBCs. Cytometry. 2000;39:285-294.

10. Neale G, Coustan-Smith E, Stow P, et al. Comparative analysis of flow cytometry and polymerase chain reaction for the detection of minimal residual disease in childhood acute lymphoblastic leukemia. Leukemia. 2004;18:934-938.

11. Engvall E, Perlmann P. Enzyme-linked immunosorbent assay, ELISA. 3. Quantitation of specific antibodies by enzyme-labeled antiimmunoglobulin in antigen-coated tubes. J Immunol. 1972;109(1): 129-135.

12. Engvall E. Enzyme immunoassay ELISA and EMIT. Methods Enzymol. 1980;70(A):419-439.

13. Flatmark K, Bjørnland K, Johannessen HO, et al. Immunomagnetic detection of micrometastatic cells in bone marrow of colorectal cancer patients. Clin Cancer Res. 2002;8:444-449.

14. Kekarainen T, Mannelin S, Laine J, Jaatinen T. Optimization of immunomagnetic separation for cord blood-derived hematopoietic stem cells. BMC Cell Biol. 2006;7:30.

15. Ijiro K, Ringsdorf H, Birch-Hirschfeld E, Hoffmann S, Schilken U, Strube M. Protein-DNA double and triple layers: interaction of biotinylated DNA fragments with solid supported streptavidin layers. Langmuir. 1998;14(10):2796-2800.

16. Kuberan B, Gunay NS, Dordick JS, Linhardt RJ. Preparation and isolation of neoglycoconjugates using biotin-streptavidin complexes. Glycoconj J. 1999;16(6):271-281.

17. Aslan FM, Yu Y, Mohr SC, Cantor CR. Engineered single-chain dimeric streptavidins with an unexpected strong preference for biotin4-fluorescein. Proc Natl Acad Sci U S A. 2005;102:8507-8512.

18. Tronc E, Belleville P, Jolivet JP, Livage J. Transformation of ferric hydroxide into spinel by iron (II) adsorption. Langmuir. 1992;8: 313-319.

19. Yang J, Peng J, Liu K, Guo R, Xu D, Jia J. Synthesis of ferrites obtained from heavy metal solutions using wet method. $J$ Hazard Mater. 2007;143(1-2):379-385.

20. Jamin N, Dumas P, Moncuit J, et al. Highly resolved chemical imaging of living cells by using synchrotron infrared microspectrometry. Proc Natl Acad Sci U SA. 1998;95:4837-4840.
International Journal of Nanomedicine

\section{Publish your work in this journal}

The International Journal of Nanomedicine is an international, peerreviewed journal focusing on the application of nanotechnology in diagnostics, therapeutics, and drug delivery systems throughout the biomedical field. This journal is indexed on PubMed Central, MedLine, CAS, SciSearch ${ }^{\circledR}$, Current Contents ${ }^{\circledR} /$ Clinical Medicine,

\section{Dovepress}

Journal Citation Reports/Science Edition, EMBase, Scopus and the Elsevier Bibliographic databases. The manuscript management system is completely online and includes a very quick and fair peer-review system, which is all easy to use. Visit http://www.dovepress.com/ testimonials.php to read real quotes from published authors. 